\title{
Application of Seismic Attributes for Detecting Different Geologic Features within Kafr EI Sheikh Formation, Temsah Concession, Nile Delta Basin
}

\author{
Mohammad Abdelfattah Sarhan ${ }^{1}$ and Mona Gomaa Safa ${ }^{1^{*}}$ \\ ${ }^{1}$ Geology Department, Faculty of Science, Damietta University, New Damietta City, 34517, Egypt.
}

Received: 11 April 2017 /Accepted: 28 June 2017

*Corresponding author: monasafa88@yahoo.com

\begin{abstract}
The seismic attributes help the interpreter to extract more information from conventional seismic data to support the geologic interpretations for the examined study area. The present work has revealed that the best seismic attributes which can be used to display the buried channels include, envelope, RMS amplitude, sweetness, chaos and spectral decomposition attributes. However, structural dip and variance attributes enhance the appearance of faults and fractures on the seismic sections.
\end{abstract}

Keywords: Seismic Attributes - Kafr El Sheikh Formation - Channels.

\section{Introduction}

The Temsah Field is located in the Temsah Concession of the Nile Delta offshore and is at about $65 \mathrm{~km}$ north-north-west of Port Said. The area extends between latitudes $31^{\circ} 45^{\prime}$ to $31^{\circ} 51^{\prime}$ $\mathrm{N}$ and longitudes $32^{\circ} 05^{\prime}$ to $32^{\circ} 10^{\prime} \mathrm{E}$. The Denise area is located in the Temsah Concession of the Nile Delta offshore and is about $70 \mathrm{~km}$ northnorth-west of Port Said and $7 \mathrm{~km}$ north-west of the Temsah Field (fig. 1). This Concession is operated since the beginning of 1992 by IEOC: as a sole partner is AMOCO Egypt Oil Company, having a participating interest of $50 \%$. 3D data became available in 1993, a Pliocene seismic feature was located at a depth of about $1500 \mathrm{msec}$ in the northwestern sector of the survey. This was a huge amplitude anomaly whose brightness and definition had been never seen in Egypt before (fig. 2). Its characteristics led to study it as a seismic bright spot (Bertello et al., 1996).

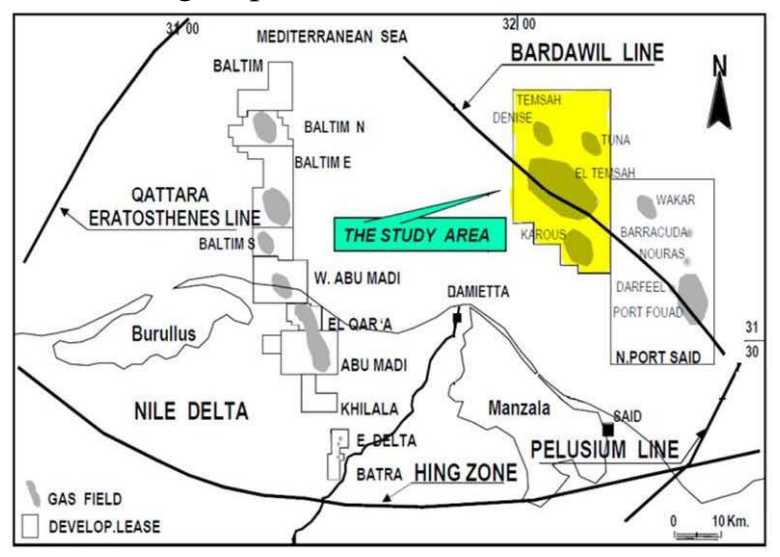

Fig (1): Location map of the Study area. 


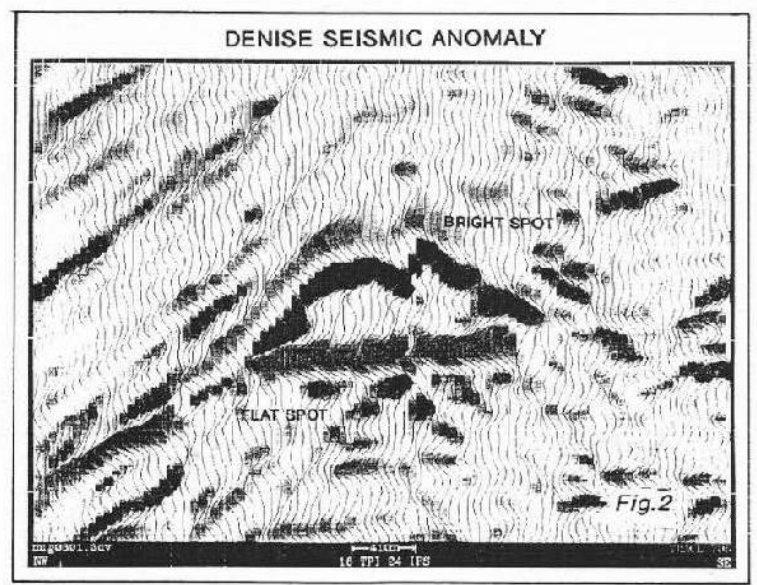

Fig (2): Denise Seismic anomaly.

Seismic attributes are the components of the seismic data, which are obtained by measurement, computation, and other methods from the seismic data. Seismic attribute analysis can extract information from seismic data that is, otherwise, hidden in the data and have been used to identify prospects, ascertain depositional environments. Hence, many new attributes were used in seismic geomorphology study. Most of these attributes are yet to be understood by many geoscientists and interpreters. The main aim of this paper is to review and introduce the most commonly used seismic attributes and their usage as interpretation tool for seismic geomorphology (Koson et al., 2014).

The seismic bright spot is a strong and anomalous amplitude event which stands out quite obviously in the overall seismic scenario. It commonly occurs in terrigenous sequences and is often associated with an accumulation of gas or light oil in sandy reservoirs. The seismic brightness is located at the top and at the bottom of the gas reservoir, and, in case it is present, at the gas-water-contact: it is due to the strong reflection coefficient produced along these interfaces by the very low seismic velocity and density of the gas or light oil. The bright spots are usually found in the shallower part of the seismic section and also in relatively recent sequences. The bright spot outlined in the Temsah area was named Denise. It is about $8 \mathrm{~km}$ in length and $1.5 \mathrm{~km}$ in width. It is located in a rollover created by the sliding of the Pliocene sequence along a big listric normal fault. Overall the Denise feature has a 4-ways dip closure. An amplitude map carried out for the top of the reservoir clearly showed the extent of the possible hydrocarbon pool. The edges of the amplitude anomaly well corresponded to the structural closure outlined by the seismic interpretation, this letting suppose that the structure was filled with hydrocarbons down to the spill point. The Denise bright spot shows an outstanding flat spot at its base. This feature was associated with the presence of a gas-watercontact. Below the culmination and in the area where thickness is the biggest, this interface shows a gentle sag which was attributed to a pull-down effect of the hydrocarbon column. The maximum vertical closure of the prospect was estimated to be $120 \mathrm{msec}$ (about $100 \mathrm{~m}$ ), Bertello et al., (1996).

\section{Available data}

The available data used in this analysis consists of a grid of $202 \mathrm{D}$ offshore seismic sections in Temsah Concessions and four drilled wells used to tie with seismic grid. The seismic profiles are taken in the NW-SE and NE-SW directions.

Temsah Seismic data Acquired at 1992 \& Bi Azimuth study conducted after new acquisition 2004 at August 2008, Bi Azimuth area is about 300 SQ Km. The objective of the Bi Azimuth study is to take the advantage of the old 1992 survey which had been acquired in perpendicular Azimuth to that of Akhen Temsah, so the net result to have two Azimuths at the same area. These data were acquired by Belayim petroleum company.

\section{Methodology}

In petroleum exploration, the first step towards a successful hydrocarbon discovery is a good subsurface image of seismic data. Seismic data is first processed to increase its signal-to-noise ratio and interpreted to determine subsurface geology. Seismic data is the output of a convolution operation between the earth reflectivity and a source wavelet. The convolution operation causes a major problem in the seismic data. It produces a band-limited trace, whose bandwidth is determined by the seismic wavelet.

Seismic attributes analysis was first used in the 1970s and 1980s in petroleum exploration after the development of complex trace theory in the early 1970s. An attribute is defined as a measurement based on seismic data, such as envelope amplitude ("reflection strength"), instantaneous phase, instantaneous frequency, polarity, velocity, dip, dip azimuth, etc (Sheriff, 1994). Seismic attributes are specific measurements of geometric, kinematic, or 
statistical features derived from seismic data (Chen and Sidney, 1997). Seismic attributes can be defined as all parameters contained in seismics (Coren et al., 2001) .

Seismic attributes are defined as all the information obtained from seismic data, either by direct measurements or by logical or experience based reasoning (Taner, 2001).

Seismic attributes are essentially derivatives of the basic seismic measurements i.e. time, amplitude, frequency and attenuation which also form the basis of their classification (Brown, 2004). It was also defined by Sheriff, 1992; as a measurement based on seismic data such as envelope, instantaneous phase, instantaneous frequency, polarity, dip and dip azimuth, etc. It is important to note that attribute interpretation supplements conventional structural interpretation and the discriminating properties of the attributes set may be critically checked for its relevance for a particular problem of a prospect. The seismic data is treated as an analytic trace which contains real components (original input trace) and the complex (imaginary) component, usually generated from the Hilbert transforms from which various amplitudes, phase and frequency attributes can be deduced (Nissen, 2002).

The application of some attributes to declares some Pliocene channels which show a bright spots, flat spots (hydrocarbon indicators) and help interpreting seismic geomorphology (faults, diapirs, unconformities and channel features) as follows:

\section{Results}

\section{Channel Detection}

\section{Cosine of Instantaneous Phase:}

Cosine of instantaneous phase is independent of amplitude and shows bedding very well. This attribute is smoother than phase (which has discontinuities) and thus is useful for automatic classification procedures, (Fig 3).

This attribute is useful as

1. Best indicator of lateral continuity,

2. Relates to the phase component of the wave propagation.

3. Can be used to compute the phase velocity,

4. Has no amplitude information, hence all events are represented,
5. Shows discontinuities, but may not be the best. It is better to show continuities Sequence boundaries,

6. Detailed visualization of bedding configurations,

Used in computation of instantaneous frequency and acceleration, (Rock Solid Images, 2003).

Fig 3 shows that Seismic section (Line No T8950 ) in original amplitude does not clearly show any obvious feature Seismic. So, the stratigraphic analysis with the cosine of instantaneous phase attribute shows obviously a $1.5 \mathrm{Km}$ channel with its internal reflection pattern with.

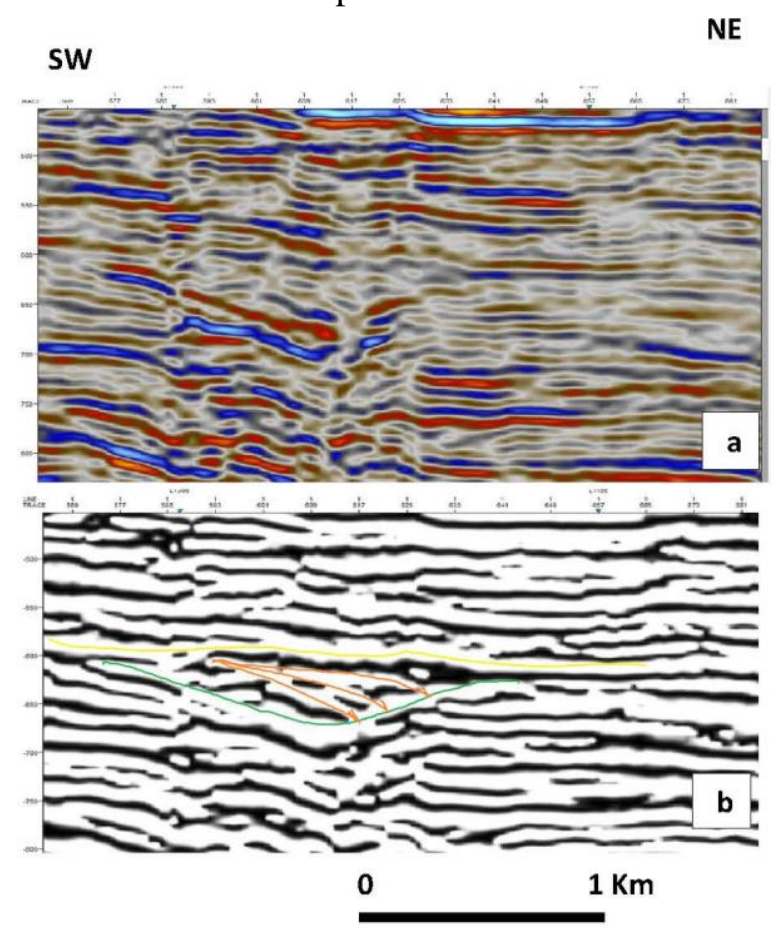

Fig. (3): (a) Seismic section (Line No T-8950) in original amplitude. (b) Seismic stratigraphic analysis shows a $1.5 \mathrm{Km}$ channel with its internal reflection pattern with the cosine of instantaneous phase attribute.

\subsubsection{Trace Gradient}

The trace gradient attribute computes the gradient along a trace between consecutive samples, equation 1.

$$
\text { TraceGradient }=f(t+K)-f(t-K)
$$

Where $K$ is the user-defined number of samples. High values of trace gradient are related with consecutive points having great changes in amplitudes. This attribute is useful to distinguish between seismic units and can be correlated with areas with abrupt changes in lithologies, related to differences in acoustic impedance (Fig 4). (Rock Solid Images, 2003).

The seismic stratigraphic analysis with Trace Gradient attribute deduced a $2.5 \mathrm{Km}$ length 
channel with is upper and lower boundaries with downlapping internal reflectors in Line No (L1016), Fig 4.

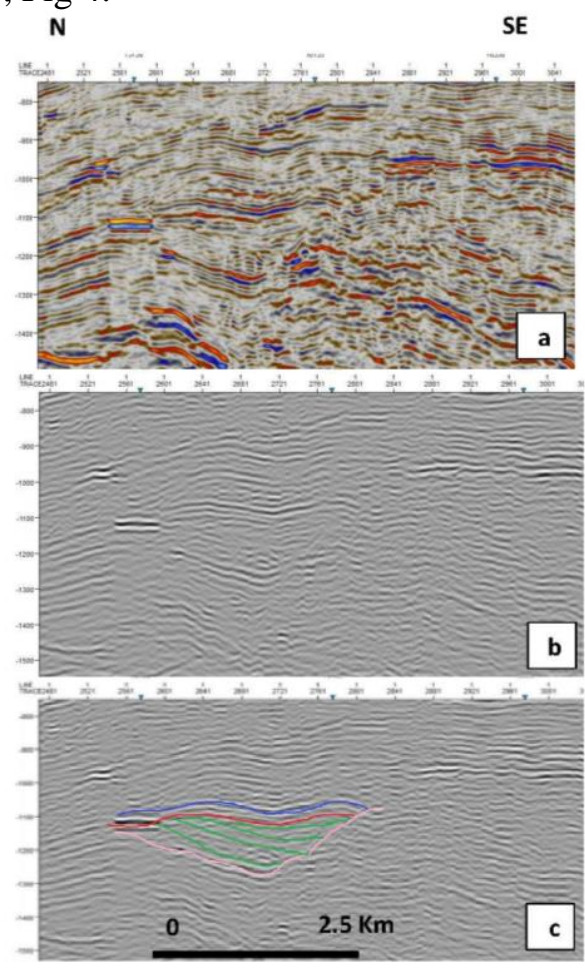

Fig. (4): (a) Seismic section (Line No L-1016) in original amplitude. (b) Seismic stratigraphic analysis with Trace Gradient attribute.(c) Interpreted channel (2.5 Km length).

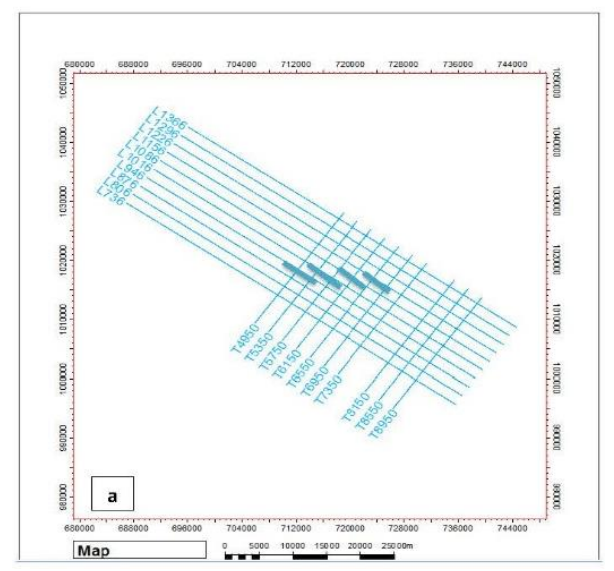

\section{Signal Envelope (E) or Reflection Strength}

The envelope is useful in highlighting discontinuities, changes in lithology, faults, changes in deposition, tuning effect, and sequence boundaries. It also is proportional to reflectivity and therefore useful for analyzing AVO anomalies. If there are two volumes that differ by constant phase shift only, their envelopes will be the same.

This attribute is good for looking at packages of amplitudes. This attribute represent mainly the acoustic impedance contrast, hence reflectivity. This attribute is mainly useful in identifying:

1. Bright spots

2. gas accumulation figure

3. Sequence boundaries, major changes or depositional environments

4. Thin-bed tuning effects

5. Unconformities

6. Major changes of lithology.

7. Local changes indicating faulting

8. Spatial correlation to porosity and other lithologic variations.

9. Indicates the group, rather than phase component of seismic wave propagation. (Rock Solid Images, 2003).

As an attribute related to the energy content of the seismic trace, it is useful to detect major and subtle lithological changes that may be difficult to interpret from the original seismic input. High values of the envelope can appear due to major lithological changes and sedimentary sequences boundaries as well as related to bright spots caused by gas accumulations. Gradual lateral changes of envelope values are often correlated with lateral variations in lithologies (Taner et al., 1979).

The bright spots probably are corresponded to channel bodies or sand layers due to an acoustic impedance contrast (Koson, 2014). As showed in Fig 5.

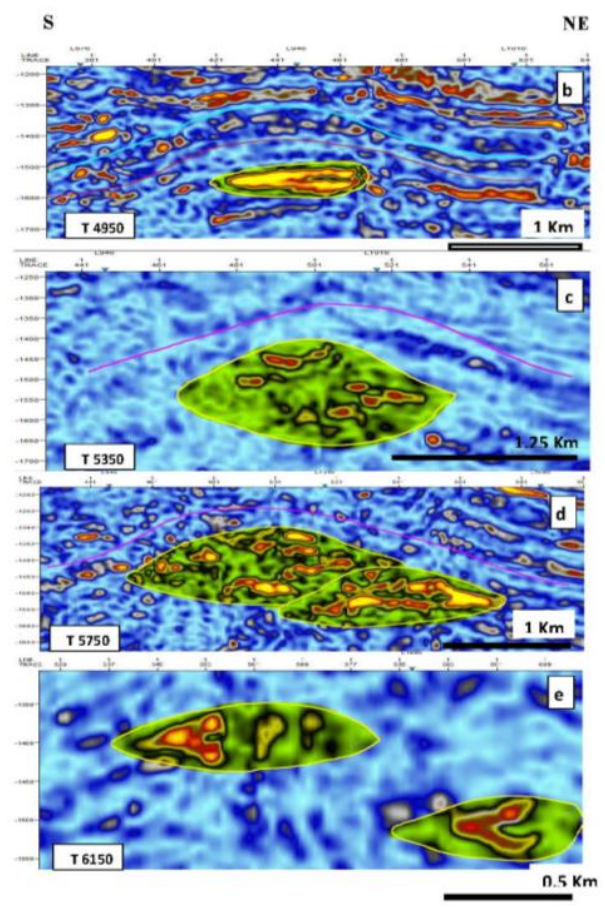

Fig. (5): Signal Envelope Attribute on a consecutive seismic lines in the NE-SW direction. .(a) the location map shows the examined seismic lines on b, c, d, e figures. 


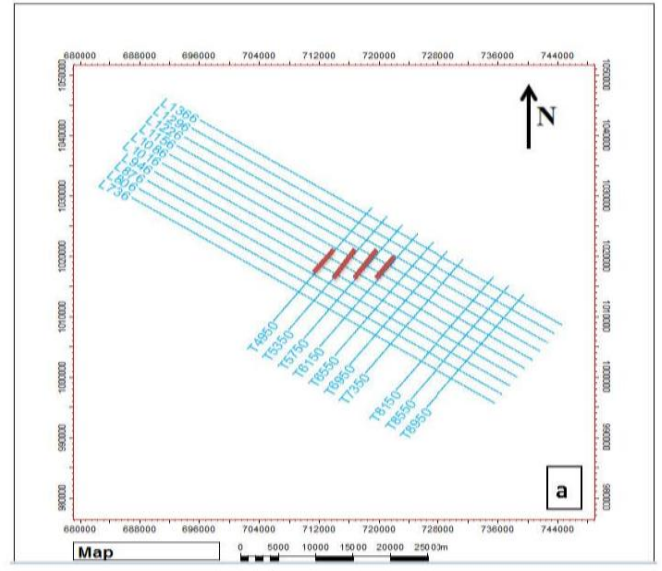

\section{RMS Amplitude}

In oil and gas industry, RMS amplitudes are traditionally computed as a surface attribute or in strata slices (Zeng et al. 1998) to build attribute maps. Computing the RMS amplitude attribute for an entire seismic cube enables the user to look at the data in a different perspective. Rendering a $R M S$ volume attribute where only high values are displayed , for example, can be used to interpret ancient channels systems and in the recognition of bright spots, Fig 6.

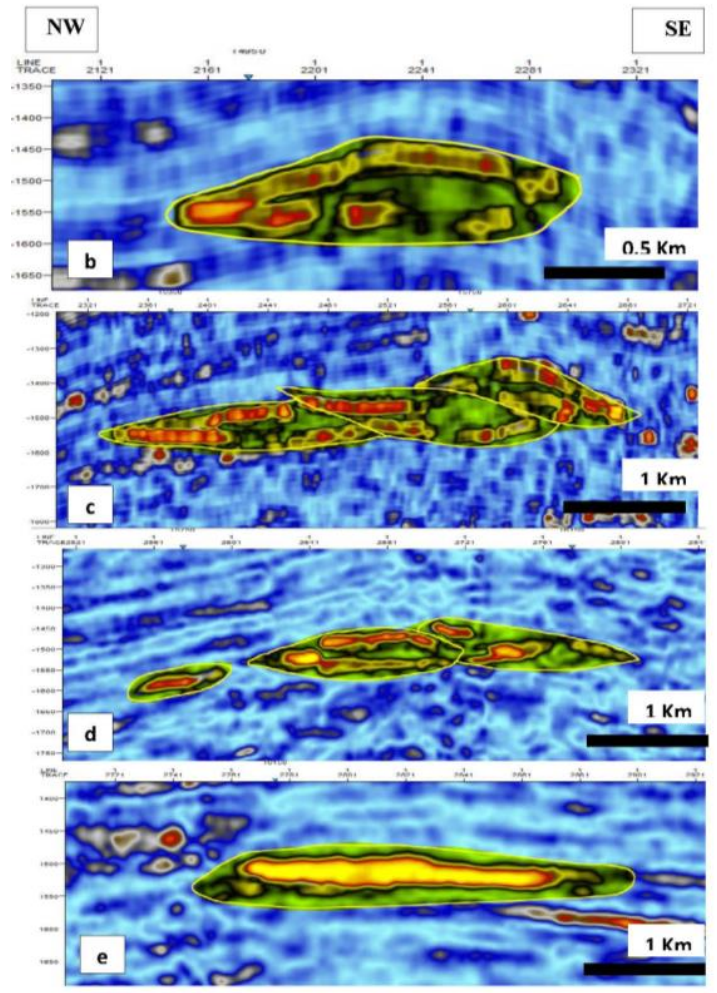

Fig. (6): RMS Amplitude Attribute on a consecutive seismic lines in the NE-SW direction.(a) the location map shows the examined seismic lines on b, c, d, e figures.

\section{Shale Diapir Detection}

\section{Chaos}

As the name suggests, the chaos attribute is related to the "lack of organization" within a 3D window. This attribute measures how consistent is the dip and azimuth orientation estimated using the principal component method (Schlumberger, 2007a). Estimated measurements with low consistency are related to a chaotic signal pattern. Chaotic patterns are used to enhance faults, discontinuities, salt bodies, and reflectors with chaotic texture which are often associated with channel infill or reef textures, Fig 7.

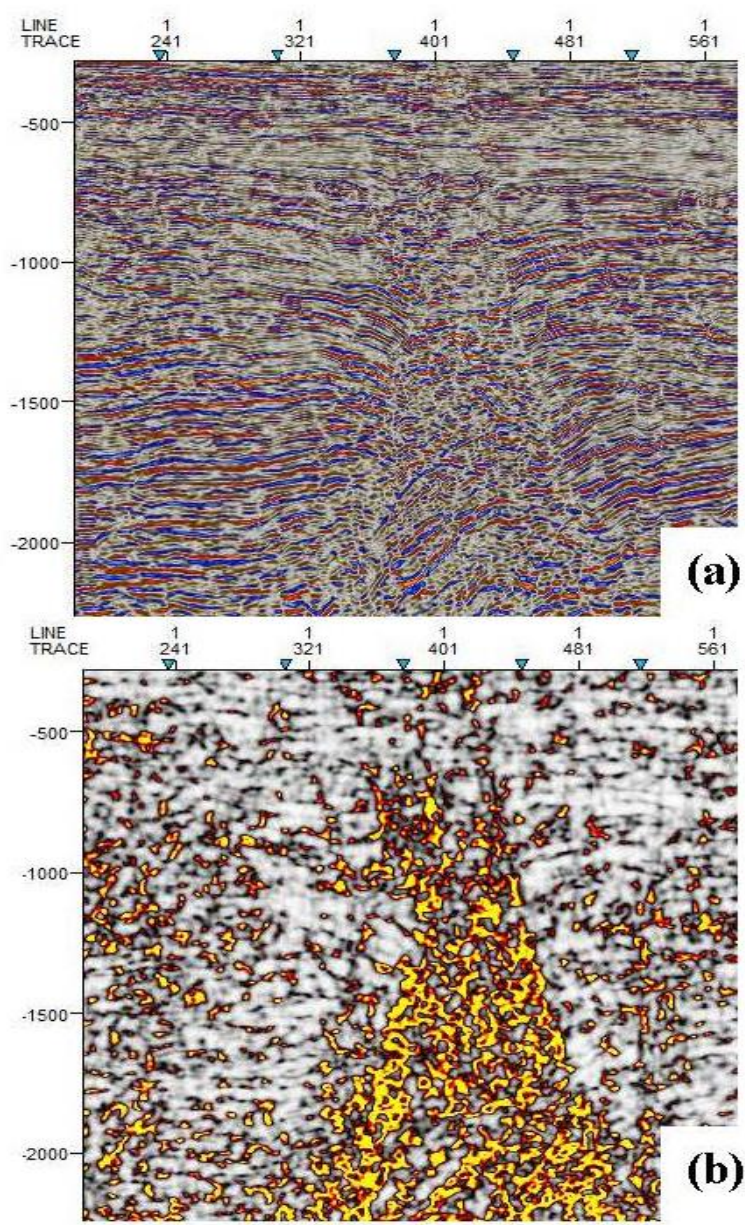

Fig. (7): (a) Seismic section in original amplitude and (b) is a Chaos attribute, three major features that chaos attribute is able to enhance can be identified: faults/discontinuities, shale intrusion and chaotic texture within reflectors.

\section{Instantaneous Frequency}

Instantaneous frequency is the time derivative of the phase, i.e., the rate of change of the phase equation 2:

$$
F(t)=d((t)) / d t
$$


Instantaneous frequency represents the mean amplitude of the wavelet.

Instantaneous frequency can indicate bed thickness and also lithology parameters.

Corresponds to the average frequency (centroid) of the amplitude spectrum of the seismic wavelet. Seismic character correlator, Indicates the edges of low impedance thin beds.

Hydrocarbon indicator by low frequency anomaly. This effect is sometimes accentuated by the Unconsolidated sands due to the oil content of the pores (Taner,2001).

Fracture zone indicator, appear as lower frequency zones. Chaotic reflection zone indicator, Bed thickness indicator.

Higher frequencies indicate sharp interfaces or thin shale bedding, lower frequencies indicate sand rich bedding. Sand/Shale ratio indicator, Fig 8.

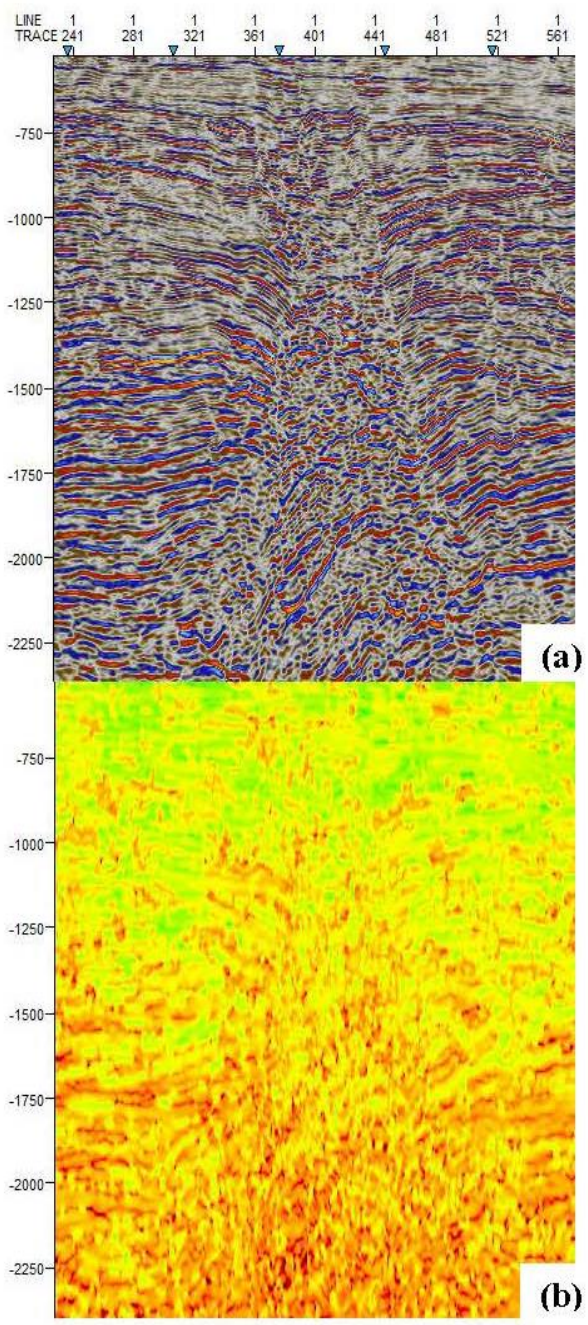

Fig. (8): (a) Seismic section in original amplitude. (b) Instantaneous Frequency showing the shale diaper.

\section{Fault Detection}

\section{Dip Deviation}

Dip deviation is a multi-trace-based seismic attribute that tracks rapid changes in the local orientation of seismic reflectors; these rapid changes can be interpreted as edges. The dip deviation algorithm considers the difference between the dip trend and the instantaneous dip. Dip estimates are computed from the local maxima of the input seismic data and from the maxima of the derivative of the input data, which are then smoothed by a Gaussian smoothing operator, Fig 9.

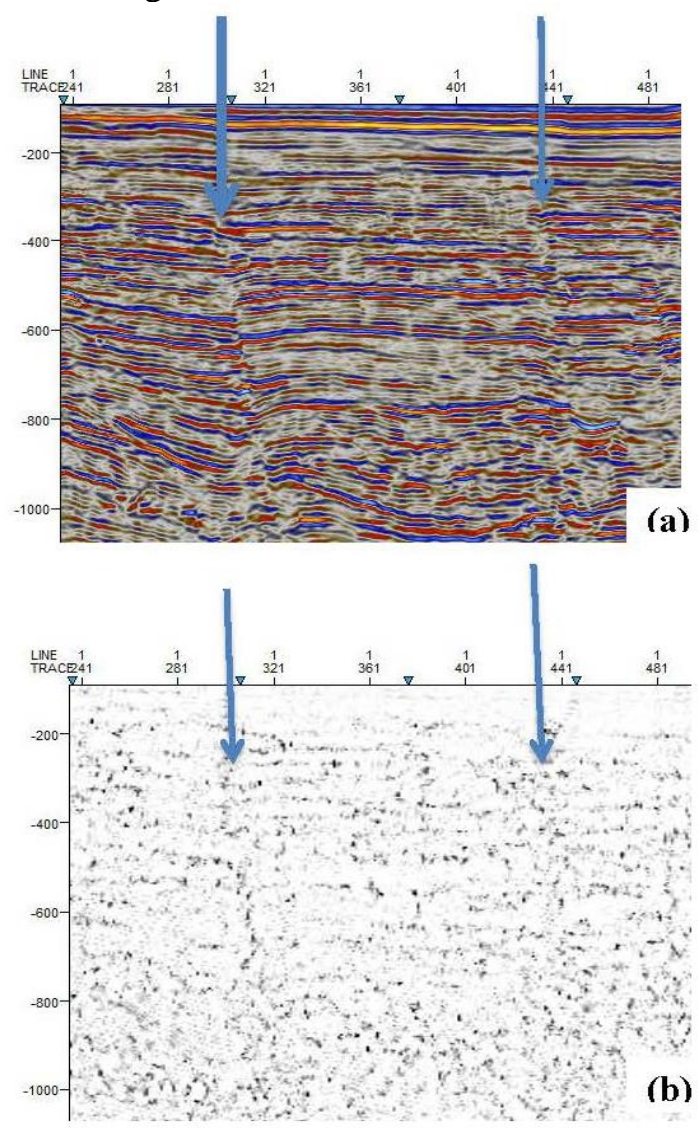

Fig. (9): Comparison between original seismic data and dip deviation attribute. (a) Seismic section in original amplitude. (b) Seismic section from a dip deviation cube displaying only dip differences bigger than $10^{\circ}$. blue arrows point towards two faults perfectly identified by the attribute.

This method has proven results in passive margins and soft rocks where the downthrown side of a fault typically shows significant dip into the fault. It has also been found to work successfully for low-angle illumination. 


\section{Structural Smoothing}

Structural smoothing is a fast volumetric signal processing method that applies a 3D Gaussian filter to reduce the noise content of the input data. This attribute performs a structure-orientated filtering since it takes into account bed estimated orientations, by the principal component estimation method. A structure-orientated filter reduces the noise content without losing information related to edges within the data.

Nowadays, the time spent in seismic data interpretation is considerably reduced when compared to the past. Costumers want fast responses with robust interpretations and reliable geological models which best fit the seismic data with the less time-consumption possible. In addition, if in the past most of the interpreters were geophysicists they have been mostly replaced by geologists that, if by one hand are able to build best geological models, by the other hand have more difficulties in distinguishing noise from real data, and have little knowledge of seismic data processing and artifacts (Fehmers and Hocker, 2003). Fast volumetric signal processing attributes, Fig 10.

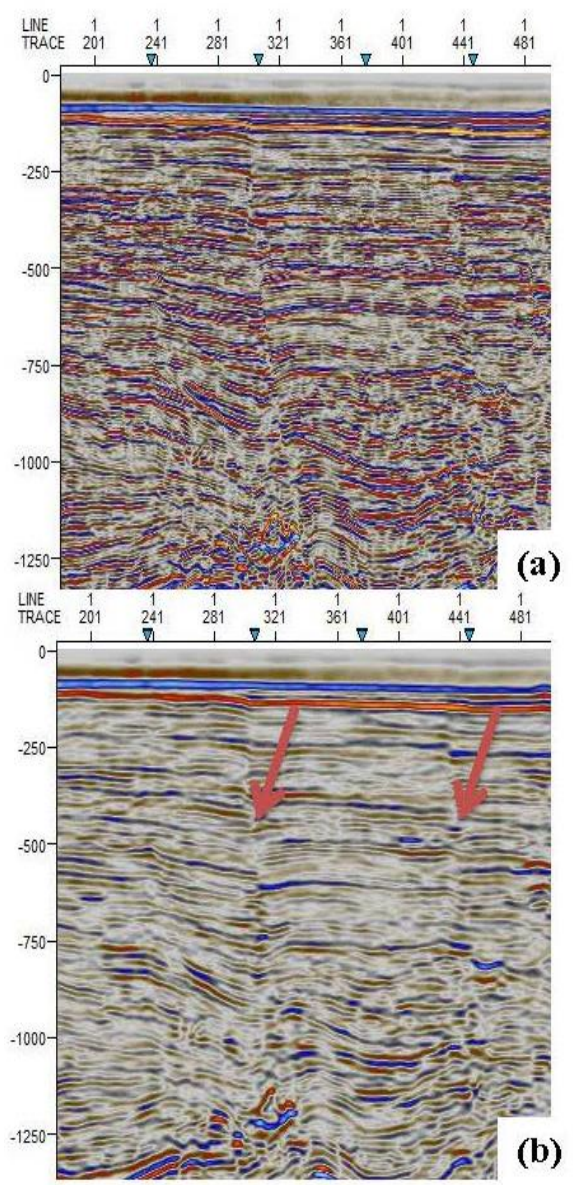

Fig. (10): Seismic section in: (a) original amplitude; (b) structural smoothing attribute.

\section{Instantaneous Phase}

Instantaneous phase enhances both weak and strong seismic events due to the invariant nature of the attribute in terms of amplitudes. This attribute has proven results enhancing reflectors continuity, discontinuities, faults and pinch-outs, (Fig 11). Seismic stratigraphy patterns (e.g. onlaps and offlaps) are easily identified with this attribute allowing the interpreter to deduce more easily the sedimentary processes that affected the area (Taner et al., 1979). Thin-bed hydrocarbon reservoirs often cause local phasing due to the presence of hydrocarbon accumulations, which explains classifying instantaneous phase as a DHI, a potential Direct Hydrocarbon Indicator (Chen et al., 1997).

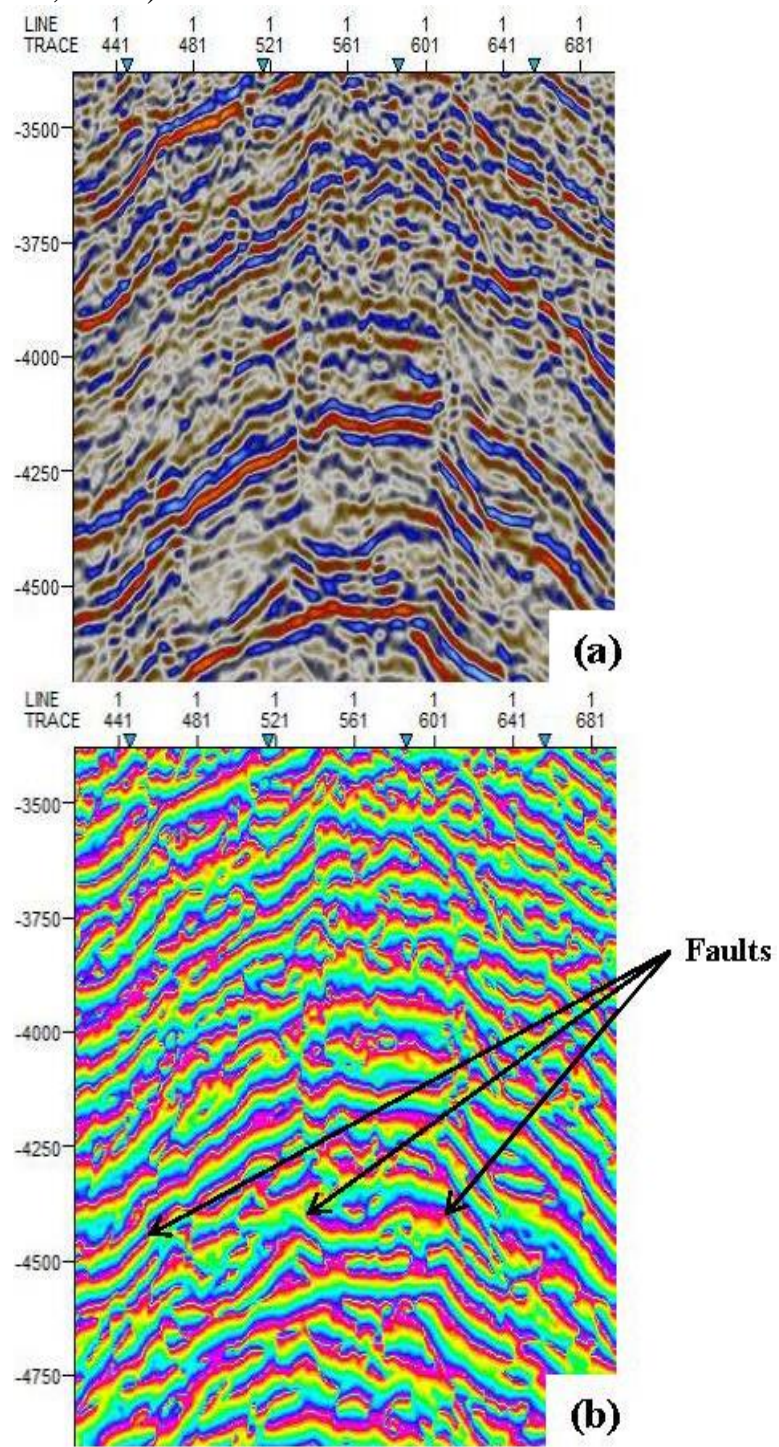

Fig. (11): Seismic section displayed in original amplitude and (b) corresponding instantaneous phase attribute where reflectors have enhanced continuity. Faults and seismic stratigraphy patterns (reflectors terminations) are better interpreted. 


\section{Variance}

The variance attribute is an edge imaging and detection method. The window size is the critical parameter to obtain discontinuities as sharp as possible. Long vertical windows produce vertical stripping while short window lengths produce horizontal stripping when variance is displayed in cross-sections (Figure 12). The size of the window can be adjusted in inline/crossline and vertical directions independently. Different values for each of the first two directions can really bring out depositional features which have a preferential directions in space (e.g. non-meandering channels), Variance attribute is proved to help imaging of channels and faults (Pigott et al., 2013) and is also used to display directly the major fault zones, fractures, unconformities and the major sequence boundaries.

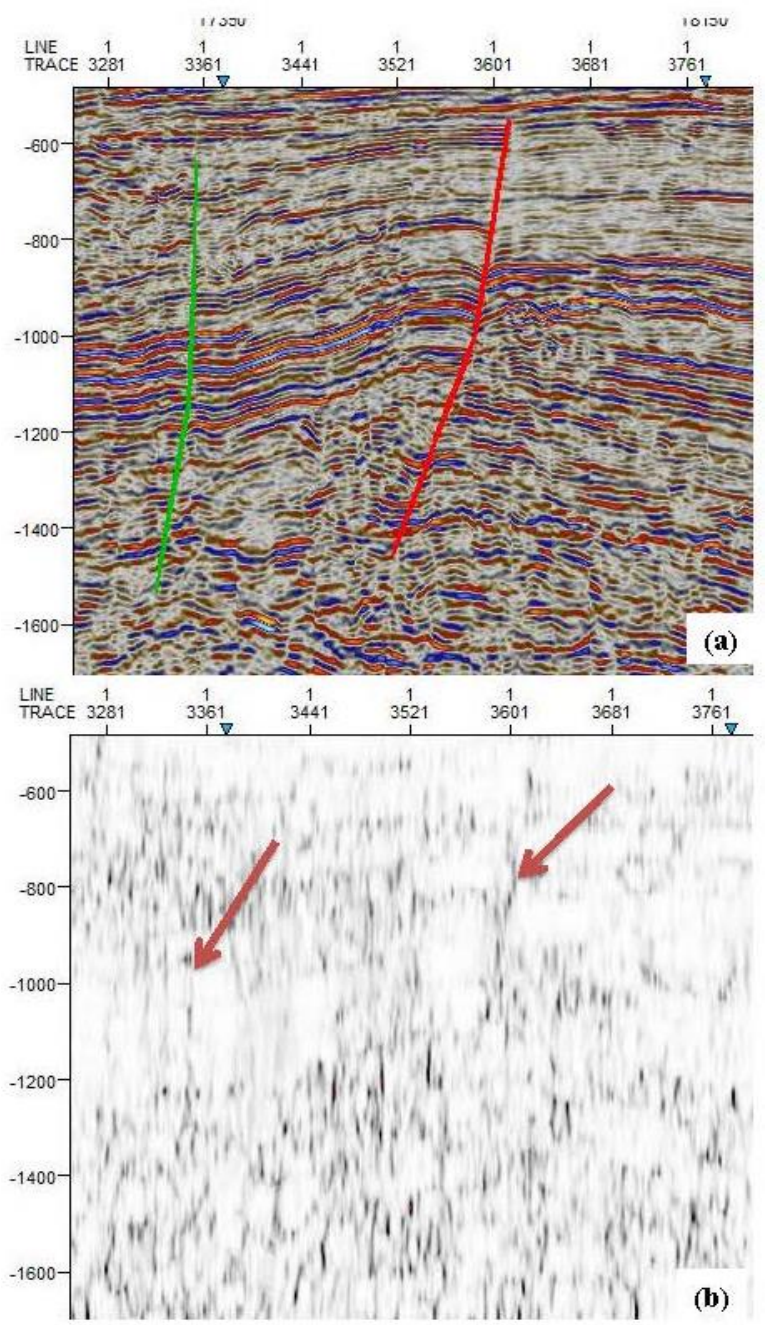

Fig. (12): Seismic section displayed in original amplitude and (b) corresponding variance attribute where Faults are better interpreted.

\section{Conclusion}

The seismic bright spots can be found usually in the shallow part of the seismic section and are good indicators of gas or light hydrocarbon accumulations, especially if a flat spot, reflecting a possible gas-water-contact, is associated.

It can help the interpreter to extract more information from conventional seismic data, which can support the geomorphology and also paleo-environments interpretation. The main types of fluvial system elements are major channels are well displayed with envelope, RMS amplitude, sweetness, chaos attribute and spectral decomposition. Structure such as faults and fractures are displayed well with structural dip and variance attribute.

Through the application of some seismic attributes such as Cosine of Instantaneous Phase, Trace Gradient, Signal Envelope and RMS Amplitude, a possible hydrocarbon reservoirs are detected as a channels vary in length from 1 to $2.5 \mathrm{Km}$ channel and stacked channels.

The shale Diapir is clearly detected by using Chaos and Instantaneous Frequency attributes. Also the structural interpretation also become easier by using Dip Deviation, Structural Smoothing, Instantaneous Phase and Variance Attributes.

\section{Acknowledgement}

The authors are grateful to the PETROBEL Petroleum Company and the Egyptian General Petroleum Corporation (EGPC) for providing the data presented in this article.

\section{References}

Bertello F, Barsoum K, Dalla S, Guessarian S (1996): Temsah discovery: A giant gas field in a deep sea turbidite environment. 13th EGPC Petroleum Exploration and Production Conference, Cairo, Egypt. 1:165-180.

Brown, A. R. (2004): Interpretation of threedimensional seismic data (pp. 247-294, 6th ed.). American Association of Petroleum Geologists Memoir 42.

Chen and S. Sidney., (1997): Seismic attribute technology for reservoir forecasting and monitoring, The Leading Edge, 445-456.

Chen and S. Sidney., (1997): Seismic attribute technology for reservoir forecasting and monitoring, The Leading Edge, 445-456. 
Fehmers, G. C., \& Höcker, C. F. (2003): Fast structural interpretation with structure-oriented filtering. Geophysics, 68(4), 1286-1293.

Images, Rock Solid. (2003): "Seismic trace attributes and their projected use in prediction of rock properties and seismic facies." Houston, Texas, 1-4.

Koson, S., (2014): Enhancing Geological Interpretation with Seismic Attributes in Gulf of Thailand. B.Sc. report, Chulalongkorn Uni., Thailand, 42 p.

Nissen, S. E. (2002): Seismic Attributes for the Explorationist. Kansas Geological Survey: Openfile Report No. 2002-49: North Midcontinent PTTC Petroleum Technology Fair.

Pennington, W. D. (1997): Seismic petrophysics: An applied science for reservoir geophysics. The Leading Edge, 16(3), 241-246.

Pigott, J.D., Kang, M.H., and Han, H.C., (2013): First order seismic attributes for clasticseismic facies interpretation: Examples from the East China Sea. Journal of Asian Earth Sciences, v.66, 34-54.
Schlumberger (2007) a: Interpreter's Guide to Seismic Attributes. 115 pp.. References 163.

Sheriff, R. E. (1992): Reservoir geophysics, Society of Exploration Geophysicist.

Sheriff, R.E., (1994): Encyclopedia Dictionary of Exploration Geophysics, Soc. Expl. Geophys.

Taner, F., V. Volpi, and U. Tinivella., (2001): Gas hydrate physical properties imaging by multiattribute analysis-black ridge bsr case history, Marine Geology J., 178, 197-210.

Taner, M T, Koehler, F, and Sheriff, R E,. (1979): Complex seismic trace analysis: Geophysics, Vol 44, pp. 1041-1063.

Taner, M. T. (2001): Seismic Attributes. Canadian Society of Exploration Geophysicists Recorder, September, 49-56.

Zeng, H., Backus, M., Barrow, K., Tyler, N. (1998) a: Stratal slicing, part I: Realistic 3-D seismic model. Geophysics, Vol. 63, 502 - 513. 